sunken hemithorax may provide some insurance against re-activation of pulmonary disease. Should the state of the lung be such that re-expansion is undesirable or impossible, thoracoplasty will both obliterate the empyema and allow the lung disease to heal. If there is gross destruction of the lung, with an associated empyema, extras pleural pneumonectomy, excising both the lun and the empyema, by dissection in the extra-. pleural plane, may be indicated.

BIBLIOGRAPHY

BARRETT, N. R. (1950), 'Techniques in British Surgery.' Philadelphia. W. B. Saunders.

\title{
ON THE TEACHING OF GERIATRICS
}

\author{
By T. N. RudD, M.D.(London), M.R.C.P. \\ Physician, the Belmont Hospital, Tiverton, Devon
}

Physicians who practise in hospitals devoted to the care of the elderly will be in general agreement with the view that many highly experienced and otherwise excellent doctors are nevertheless lacking in their approach to disease in old age. They adopt what will later be described as a 'negative approach,' characterized by an attitude of frustration and laisser-faire. When the doctor concerned is a general practitioner his attitude will, in addition, be coloured by the great difficulties which attend the care of the very old in their homes. There is, however, another and a positive approach to the subject, the adoption of which has resulted in many improvements, made during the last decade, in the care of the elderly in hospitals. More intensive study of old people's illnesses has led to the development of a technique of geriatrics. Knowledge of this technique is at present in its early childhood and so far there has been, in this country at least, little organized teaching of the subject. Textbooks on the diseases of the aged have appeared in America, where there is also a bimonthly journal (Geriatrics) ' devoted to research and clinical study of the aged and ageing.' In this country no textbook has been produced, while such articles as have appeared under geriatric titles have been usually of an administrative rather than a clinical nature. Clinical problems of disease in the elderly have received little attention from British teaching centres, although at least one teaching hospital in London has appointed a lecturer in geriatrics. The urgency of the problems of disease in the aged warrants a much more intensive teaching of the subject.

When teaching of such a nature is considered, several great questions immediately present themselves. These can be summarized under the headings Why? When? Whom? Where? What and How? It is under these headings that the teaching of geriatrics will be considered.

\section{Why Should Geriatrics be Taught?}

Geriatrics should be taught for three main reasons:-

(I) There is considerable ignorance among sections of the medical and nursing professionstas to what can be achieved by a positive, active approac $h$ to therapy, even in the very old. The variations $w h i h$ diseases show, when they presento themselves in aged subjects, are not, as yet, widelp understood and many disease conditions remai $\vec{B}$ untreated, either because cure at such an age is considered not worth while, or because the risk of therapy has not been balanced against the dis? advantages of leaving the patient untreated. Mucto more treatment, both medical and surgical, could advantageously be given in the later years of life The completion of second stages of prostatectom operations is a case in point.

(2) It is economically imperative to keep the elderly self-supporting physically, and indepens dent of care by relatives and hospitals. Sheldop (1950) has pointed out that it is probable that the. wage-earning population is already bearing itto maximum load of chronic sickness and that it cannot carry any additional burden withou reducing industrial output. Unless the elderly are less dependent in the future (when their numbers will be proportionately greater than today) that they are at present, the country will be faced wit a grave problem.

(3) Preventive medicine in recent decades ha\$ added years to the life of the community. Thes years will be neither happy nor fruitful unles? 
social medicine can give ' life to the years.' Life does not consist in just ' not being dead,' and extra years of life are burdensome if they are years of incapacity and boredom. Much economic wastage at present occurs through workers retiring at the accustomed age and while their services are still of value to the community. The future is likely to demand from each one of us extended years of community service; sound geriatric medicine will help in giving health to these later years of service to the community.

\section{When to Teach Geriatrics}

Since clinical geriatrics is a branch of general clinical medicine, geriatrics should not be taught until the rudiments of general clinical medicine have been grasped. It should therefore be part of the final-year medical course. The possibilities and techniques of geriatric medicine should be taught to postgraduate students and general practitioners in refresher and postgraduate courses whenever the opportunity arises.

\section{Whom to Teach}

Medical students, nursing students, qualified nurses and medical practitioners all need a working knowledge of this important subject. Nursing students in particular should have experience of work in geriatric departments, not only to teach them the fundamentals of nursing, but also to teach them how to handle the old successfully. Acute wards of hospitals, where the bulk of our student nurses are taught, tend to become stripped of chronic cases. The modern probationer nurse, therefore, lacks the broad experience of her predecessor in nursing the chronic sick and her nursing technique suffers accordingly. A tour of duty in the geriatric wards will correct this deficiency in the modern nurse's curriculum. Many skilled qualified nurses could also benefit by refresher courses in nursing old people by modern methods. Doctors of all types need instruction in what can be done for the elderly. It must be remembered how recent is the change in attitude which has produced the department of medicine known as geriatrics.

\section{Where Should Geriatrics be Taught?}

Geriatrics should be taught wherever doctors and elderly patients are brought together. The three most important places for teaching are:-

(I) In the geriatric unit by routine ward rounds, clinical conferences and postgraduate courses.

(2) In general hospitals, where the problems of old age should be given due prominence in teaching if the student is to keep his sense of proportion regarding the field conditions which he will subsequently encounter.
(3) In the post-mortem room, provided there can be careful correlation between clinical and autopsy findings. Valuable as these demonstrations are to students, their value to geriatrics physicians, who can check up after death, or the clinical findings during life, is much greater.

In universities, therefore, geriatrics should be taught as vigorously as paediatrics. The great disproportion between attention given in most university medical schools to the two extremes of life is very striking. Very few medical schools to date have appointed teachers in geriatrics!

\section{What to Teach}

A negative must first be stressed. Teaching of geriatrics must never become a mere repetition of the lessons already learned in general medicine, with occasional reference to advancing years. The basis of general medicine should be taught as it is at present, or with such variations as broadening experience shall dictate. When this basis has been taught, geriatric conceptions should be added as a sort of superstructure. The first subject to be taught in this department should therefore be:-

\section{(1) The Variations of Disease in Old Age}

This is a very broad subject which could fill कs textbook. Disease in later life can present a pictures very different from that in childhood. Certain conditions, such as the neoplasms, are frequentl迹 silent and slow growing. Others, such as acutè appendicitis, frequently run a much more rapid course. There is, in addition, the constant impingement on other disease conditions, of the degenerations associated with age, noticeably arteriosclerosis of every organ of the body. Double pathology thus becomes almost constant rather than unusual. Finally, there are the conditions, rarely met with in the earlier age-groups, which are comparatively common in old age. Prominent among these is senile osteoporosis of the spine, with its symptomatic severe 'rheumatic' pains.

\section{(2) The Fundamentals of Geriatrics}

These comprise the handling of the patient and the entire policy governing his stay in hospital. The prime factor here is rehabilitation, the " reabling ' of the patient to take his place in society (Rudd, 1950), and, with that aim in view, the treatment of every discoverable defect, whether of a major or minor nature, which may impede the patient in his struggle for existence. The student will here be taught that the inevitable deterioration in certain patients must not be allowed to minimize effort on behalf of those patients in whom prognosis is better. $\mathrm{He}$ will also be taught that geriatrics does not seek the impossible, i.e., rejuvenation, but aims at setting the patient once

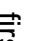

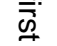
然

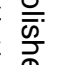
年 $\%$ . U

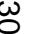
然

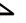

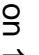
$\overrightarrow{3}$ $\vec{g}$ ( 
again on his feet as a self-supporting individual. He will be shown the defeat of the bed-fast state and the frequent abolition of incontinence by getting the patient up, by occupying his mind and hands (in occupational therapy), and by restoring ambition.

\section{(3) New Concepts in Disease}

The 'wholeness' of health should be no new conception. When, however, undue attention is given to one organ of the body in dysfunction the whole patient is apt to be neglected. Factors which have an important bearing on the organ in question are then forgotten. Geriatrics speedily teaches that the body as a whole must be treated if success of any permanency is to be obtained. For instance, mild degrees of heart failure will frequently not clear until associated anaemia is treated.

Next, a functional approach is constantly required. The important question is frequently, not what has made this heart go wrong, but what is its present capacity for work and how can it be helped in its task.

The third conception is of the affected bodily system rather than the organ. Such a conception should, of course, be held for every period of life, but in geriatrics, when functional capacity is in the forefront, this attitude is of constant importance. The latest integration of this nature has just been made in the U.S.A., where Steinbrocker and others (1950) have developed the helpful conception of musculoskeletal inadequacy and failure in the study of orthopaedic difficulties of the aged.

\section{How to Teach Geriatrics}

The training of teachers in clinical medicine is, in this country, still in the embryo stage and ideas on the subject are mostly not fully worked out. Certain ideas are, however, clear:-

(I) The teacher must be an enthusiast for his subject, and the time spent in teaching and learning should be a time of mutual enjoyment.

(2) He must be clinically competent, and preferably occupied, for the greater part of his professional life, in handling the subjects about whom he teaches. Through a clear understanding of his patients' personal needs and problems he should impress his students with the necessity for thorough treatment of disease in the aged and with an understanding of the difficulties peculiar to old age. He will thus teach humanity in dealing with the elderly. At the same time, he will show how asocial problem of the greatest magnitude can beㄹ helped by individual effort of practising doctors -

(3) He must teach a technique; that is to say $\overrightarrow{\overrightarrow{\vec{B}}}$ something of practical importance by which something can be gained. Handling of old persons is? a thing that does not come naturally; it requires learning. Once gained, that learning can be puf्e to good use.

(4) He must be aware of possible mental atti $\mathrm{i}^{£}$ tudes of his students towards what they are beings taught. They may approach him and the subject in question in either a positive or a negative way

The Positive Approach: (a) That geriatrics is subject of importance and interest; $(b)$ that there is something to be taught (i.e. not a ' hash+v up ' of what has been already learned); (c) that the teacher is imparting a new and valuable technique.

The Negative Approach: (a) That the curricu $\overrightarrow{\vec{A}}$ lum is already overcrowded; (b) that the subject is dull and that age is dirty, depressing or other- wise distasteful; (c) that as death is inherentl at hand effort is wasted (the approach of frustration).

Questions to students and the results of ofser cussion will speedily reveal the attitude of class. So long as black spots in the institutiong treatment of old people exist, none who have seens them can continue to hold the approach of frustra tion once they have seen modern geriatrics praco tised. When such black spots have disappeared students will still be able to see cases which stayed too long away from application of modern methods for a cure or rehabilitation ever to be effected.

\section{Conclusion}

The increasing proportion of old to younge? members of the community makes healthy and independent old age a social necessity. A know. ledge of the possibilities and limitations of the geriatric technique should be made generar throughout medicine and its associated professions. The questions why, when, whom, where, what and how to teach geriatrics are considered in order

\section{BIBLIOGRAPHY}

RUDD, T. N. (1950), Practitioner, 164, 549.

SHELDON, J. H. (1950), Brit. med. F., i, 319.

STEINBROCKER, I., et al. (1950), Geriatrics, 5, 121 